\title{
Tetrahymena telomerase catalyzes nucleolytic cleavage and nonprocessive elongation
}

\author{
Kathleen Collins and Carol W. Greider \\ Cold Spring Harbor Laboratory, Cold Spring Harbor, New York 11724 USA
}

\begin{abstract}
Telomerase is a ribonucleoprotein enzyme that adds telomeric repeats to chromosomes, maintaining telomere length and stabilizing chromosome ends. In vitro, telomerase from the ciliate Tetrahymena elongates single-stranded, guanosine-rich DNA primers by adding repeats of the Tetrahymena telomeric sequence, $\mathrm{dT}_{2} \mathrm{G}_{4}$. We have identified two activities of Tetrahymena telomerase in addition to the previously described processive elongation reaction: a $3^{\prime}-5^{\prime}$ nucleolytic cleavage of primer or product DNA and a nonprocessive mode of elongation. The nucleolytic cleavage activity removed residues not conforming to the telomeric repeat sequence from a primer $3^{\prime}$ end, eliminating mismatch between DNA primer and RNA template sequences. Template-matched residues were also cleaved from primer or product DNA. Specific primer lengths, sequences, and concentrations stimulated cleavage and processive or nonprocessive elongation differentially. These newly identified activities suggest that telomerase may catalyze a range of telomere synthesis and repair functions and suggest mechanistic similarities between telomerase and RNA polymerase enzymes. On the basis of our results, we propose a model for telomerase primer binding, cleavage, and elongation.
\end{abstract}

[Key Words: Telomerase; telomere; polymerase; nuclease; processivity]

Received February 10, 1993; revised version accepted May 10, 1993.

The ends of linear chromosomes, termed telomeres, serve specialized functions. Telomeres stabilize chromosomes from illegitimate recombination, affect the expression of telomere-proximal genes, and may contribute to chromosome organization in the nucleus (for review, see Blackburn 1991; Greider 1991a). Loss or mutation of telomeric regions can result in high frequencies of recombination, failure of chromosome segregation or cell division, and loss of expression of telomeric genes (McClintock 1941; Biessmann and Mason 1988; Levis 1989; Yu et al. 1990). The only identified DNA sequence element common to telomeres is a cap of simple-sequence repeats at the extreme chromosome termini. Among different species, these repeats can be invariant or degenerate, with each repeat ranging in length from 3 to $10 \mathrm{bp}$ (for review, see Greider 1990). All identified telomeric simple-sequence repeats share a bias of deoxyguanosine-rich sequence in the DNA strand running $5^{\prime}$ to $3^{\prime}$ toward the chromosome end.

Chromosome replication by conventional DNA polymerases is predicted to replicate telomeric DNA incompletely (Watson 1972; Olovnikov 1973). Synthesis of lagging strand DNA proceeds by elongation of a short RNA primer, which is subsequently degraded. After elongation and degradation of the most terminal RNA primer, a region of unreplicated DNA would remain. This incomplete replication, if uncorrected with each cell gen- eration, would result in a decrease in the length of simple-sequence repeats at the end of a telomere. A reduction in length of telomeric DNA restriction fragments has been observed with passaging of primary cells in culture (Harley et al. 1990; Counter et al. 1992), with age of human donors in blood or fibroblast cells (Hastie et al. 1990; Allsopp et al. 1992), and in mutant strains of yeast and Drosophila (Beissmann and Mason 1988; Levis 1989; Lundblad and Szostak 1989|. However, this shortening of telomeric DNA restriction fragments does not occur in single-celled eukaryotes or in immortalized cell cultures that have survived crisis (Counter et al. 1992).

One mechanism for adding back simple-sequence repeats to a chromosome end was discovered in the ciliate Tetrahymena. An enzyme was detected in Tetrahymena extracts that elongated single-stranded, guanosine-rich DNA primers by de novo addition of telomeric simplesequence repeats (Greider and Blackburn 1985). This enzyme, telomerase, subsequently has been shown to elongate chromosomes in vivo ( $Y u$ et al. 1990; Yu and Blackburn 1991). Telomerase is a ribonucleoprotein complex, with both RNA and protein components essential for activity (Greider and Blackburn 1987). The 159-nucleotide Tetrahymena telomerase RNA contains a 9-nucleotide sequence complementary to 1.5 repeats of telomeric DNA, 5'-CAACCCCAA-3' (Greider and Blackburn 1989). This sequence provides the template for 
addition of $\mathrm{dT}_{2} \mathrm{G}_{4}$ repeats to primers in vitro and in vivo (Greider and Blackburn 1989; Yu et al. 1990).

Although many deoxyguanosine-rich, single-stranded DNAs are elongated by Tetrahymena telomerase, primer DNA length and sequence affect the amount of product synthesized (Greider and Blackburn 1987; Blackburn et al. 1989; Harrington and Greider 1991). Similar variation in the elongation efficiencies of guanosine-rich primers has been demonstrated for human telomerase (Morin $1989,1991)$. In vitro, Tetrahymena telomerase adds processively multiple $\mathrm{dT}_{2} \mathrm{G}_{4}$ repeats to a single primer before dissociating from the elongated product /Greider $1991 \mathrm{~b})$. In vivo, however, repeats added to chromosome termini in Tetrahymena cells expressing two different telomerase RNAs are an interspersed mixture of the repeats encoded by each RNA, which may indicate nonprocessive elongation (Yu et al. 1990; Yu and Blackburn 1991). In this paper, we demonstrate new activities for Tetrahymena telomerase. We show that Tetrahymena telomerase catalyzes a $3^{\prime} \rightarrow 5^{\prime}$ nucleolytic cleavage activity that can remove template-matched or templatemismatched nucleotides from a primer or product $3^{\prime}$ end. We also demonstrate a nonprocessive mode of elongation in vitro, preferentially stimulated by short $<10$ residues) primers of $\mathrm{dT}_{2} \mathrm{G}_{4}$ sequence or by deoxyguanosinerich, nontelomeric repeat primer DNAs. These findings are interesting in light of recent studies showing that RNA polymerases can cleave their transcripts nucleolytically (for review, see Kassavetis and Geiduschek 1993) and are also known to abort synthesis of transcripts shorter than 10 residues (for review, see von Hippel et al. 1984). Thus, the ribonucleoprotein enzyme telomerase may share common properties with DNA-dependent RNA polymerases and may catalyze several substratespecific activities in vivo.

\section{Results \\ Permuted telomeric primers are not elongated equivalently}

The $3^{\prime}$ ends of primers elongated by telomerase are thought to align or hybridize with template RNA sequence, resulting in the completion of a partial telomeric repeat before the addition of subsequent repeats (Greider and Blackburn 1987; Blackburn et al. 1989). We tested the effect of differently permuted telomeric repeat sequences on the amount of product DNA synthesized, assaying synthesis of only the first repeat added to primers by performing reactions in the presence of $\left[{ }^{32} \mathrm{P}\right] \mathrm{dGTP}$ and dideoxythymidine triphosphate (ddTTP). Four primers with permuted telomeric repeat sequence, each 18 residues in length, were reacted with telomerase (Figure 1A). The permuted primers $d\left(G_{4} T_{2}\right)_{3}, d\left(G_{3} T_{2} G\right)_{3}, d\left(G_{2} T_{2} G_{2}\right)_{3}$, and $d\left(G_{2} \mathrm{G}_{3}\right)_{3}$ were elongated by up to the number of nucleotides expected from the copying of the template RNA sequence. For example, the primer $d\left(G_{4} T_{2}\right)_{3}$ was elongated by $\leqslant 4$ dGTP and 1 ddTTP nucleotide (lane 1), whereas the primer $d\left(\mathrm{GT}_{2} \mathrm{G}_{3}\right)_{3}$ was elongated only by $\leqslant 1$ dGTP and 1 ddTTP nucleotide (lane 4). Each primer stimulated synthesis of a comparable amount of the longest product DNA, independent of the template position of synthesis initiation. However, elongation of the primer $d\left(G_{3} T_{2} G\right)_{3}$ generated an unexpected product DNA at the size of the 18-residue primer itself. As a marker and to determine primer purity, the gel-purified primers were end-labeled with $\left[{ }^{32} \mathrm{P}\right] \mathrm{ddATP}$ by terminal deoxytransferase, resulting in an oligonucleotide that migrated slightly faster than the primer +1 deoxynucleotide product. The shortest product of the telomerase reaction of $d\left(G_{3} T_{2} G\right)_{3}$ migrated notably faster than the ddATP-labeled $d\left(G_{3} T_{2} G\right)_{3}$ primer, at the position of the 18-residue input primer (lane 2).

Several lines of evidence suggest that the primer-sized product of $d\left(G_{3} T_{2} G\right)_{3}$ did not result from a contaminating, nontelomerase DNA polymerase or from nuclease activity. First, addition of deoxynucleotides to primer DNA by telomerase but not by other DNA polymerases is sensitive to RNase, which degrades the RNA component of telomerase (Greider and Blackburn 1987, 1989). Synthesis of the primer-sized products of $d\left(G_{3} T_{2} G\right)_{3}$ and other primers described below was sensitive to pretreatment of the extract with RNase (Fig. 1B). Second, the ratio of primer-sized to longer products remained constant in telomerase reactions across fractions from a glycerol gradient, assayed in the presence of $\left[{ }^{32} \mathrm{P}\right] \mathrm{dGTP}$, ddTTP, and the primer $d\left(G_{3} T_{2} G\right)_{3}$ (Fig. 1C, lanes 13-18). If a component other than telomerase were required for synthesis of the primer-sized product, the ratio of primer-sized to longer products would likely vary across these gradient fractions as a result of separation of telomerase and nontelomerase activities. Assays of the glycerol gradient fractions with the primer $d\left(G_{4} T_{2}\right)_{3}$ demonstrated that the same fractions that elongated $d\left(G_{3} T_{2} G\right)_{3}$, fractions 20-28, also elongated $d\left(G_{4} T_{2}\right)_{3}$ in reactions with $\left.{ }^{32} \mathrm{P}\right] \mathrm{dGTP}$ and either TTP (lanes $\left.1-6\right)$ or ddTTP (lanes 7-12).

The possibility remained that a small fraction of $\mathrm{d}\left(\mathrm{G}_{3} \mathrm{~T}_{2} \mathrm{G}\right)_{3}$ added to the telomerase reaction was shorter by 1 nucleotide and was not detected by labeling with terminal deoxytransferase. Enzymatically very efficient nucleotide addition to this hypothesized 17-residue primer could result in synthesis of the primer-sized product. In this case, the amount of total primer required for half-maximal activation of synthesis of the primer-sized product should be greater than the amount of primer required for half-maximal activation of synthesis of other products, assuming comparable binding affinities of these primers. We compared the primer concentration dependence of synthesis of the products of $d\left(G_{3} T_{2} G\right)_{3}$ and $d\left(G_{4} T_{2}\right)_{3}$ in the presence of $\left[{ }^{32} \mathrm{P}\right] \mathrm{dGTP}$ and ddTTP (Fig. 2A). Synthesis of the primer-sized, 18-residue product of $d\left(G_{3} T_{2} G\right)_{3}$ and the 19-residue product of $d\left(G_{4} T_{2}\right)_{3}$ occurred with a similar $K_{\mathrm{m}}$ of primer activation, $1.5 \mu \mathrm{M}$ (Fig. 2B). The primer concentration dependence of synthesis of these first nucleotide addition products of $d\left(G_{3} T_{2} G\right)_{3}$ and $d\left(G_{4} T_{2}\right)_{3}$ contrasted with the primer concentration dependence of synthesis of the maximum length products of $d\left(G_{3} T_{2} G\right)_{3}$ and $d\left(G_{4} T_{2}\right)_{3}$ in the presence of dGTP and ddTTP (22 or 23 residues in length), 

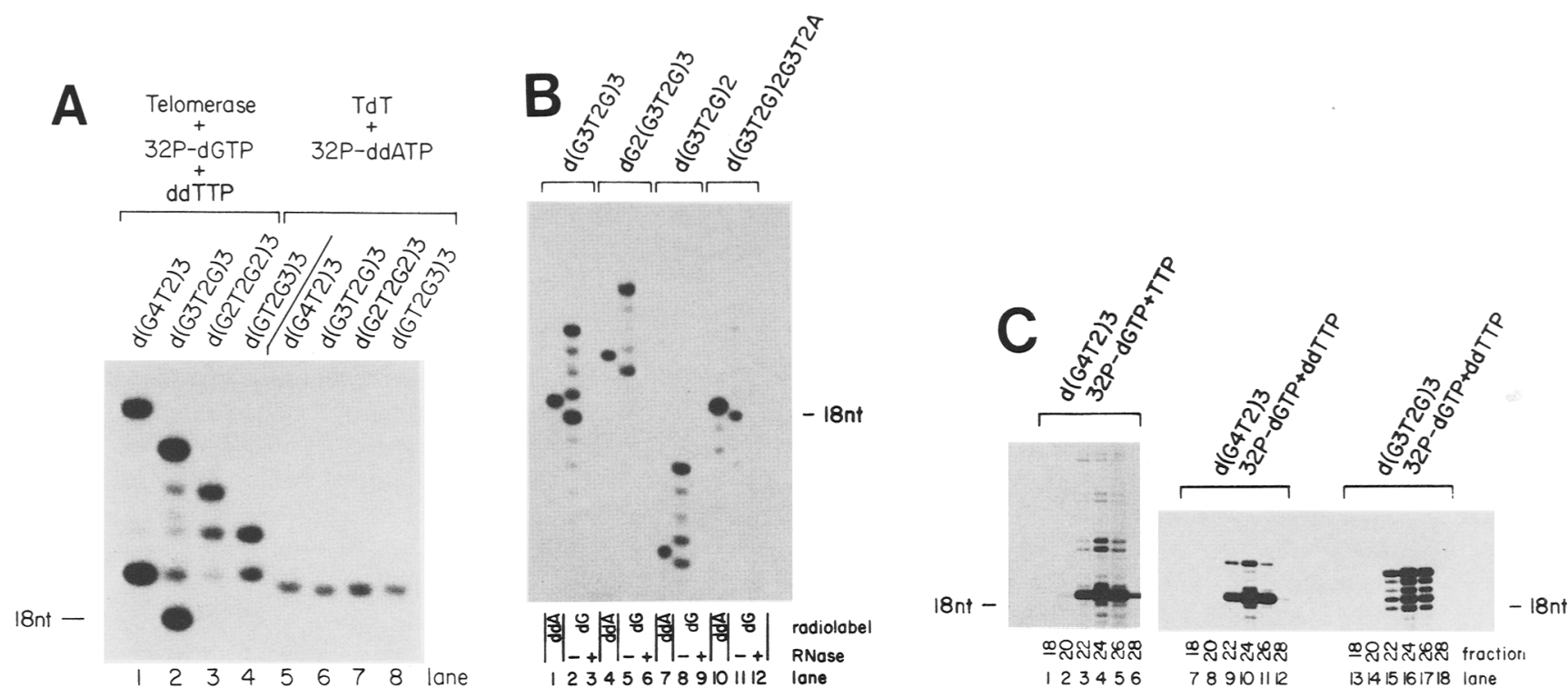

Figure 1. Synthesis of the first repeat of product DNA. Reactions were performed as described, and product DNA was precipitated, separated by PAGE, and subjected to autoradiography (for details, see Materials and methods). In each panel, the migration of an 18-residue telomeric repeat primer is indicated $(18 \mathrm{nt})$. $(A)$ The primers $\mathrm{d}\left(\mathrm{G}_{4} \mathrm{~T}_{2}\right)_{3}$ (lanes 1,5$), \mathrm{d}\left(\mathrm{G}_{3} \mathrm{~T}_{2} \mathrm{G}_{3}(\right.$ lanes 2,6$), \mathrm{d}\left(\mathrm{G}_{2} \mathrm{~T}_{2} \mathrm{G}_{2}\right)_{3}($ lanes $3,7)$, and $d\left(\mathrm{GT}_{2} \mathrm{G}_{3}\right)_{3}$ (lanes 4,8$)$ were incubated with telomerase, $\left[{ }^{32} \mathrm{P}\right] \mathrm{dGTP}$, and ddTTP (lanes 1-4) or with term:nal deoxytransferase and ${ }^{32} \mathrm{P}$ )ddATP (lanes 5-8). (B) The primers $\mathrm{d}\left(\mathrm{G}_{3} \mathrm{~T}_{2} \mathrm{G}\right)_{3}$ (lanes 1-3), $\mathrm{dG}_{2}\left(\mathrm{G}_{3} \mathrm{~T}_{2} \mathrm{G}\right)_{3}$ (lanes 4-6), $\mathrm{d}\left(\mathrm{G}_{3} \mathrm{~T}_{2} \mathrm{G}\right)_{2}(\mathrm{lanes} 7-9)$, and $\mathrm{d}\left(\mathrm{G}_{3} \mathrm{~T}_{2} \mathrm{G}\right)_{2} \mathrm{G}_{3} \mathrm{~T}_{2} \mathrm{~A}$ (lanes 10-12) were reacted with telomerase, [32P]dGTP, and ddTTP either without $($ lanes 2,5,8,11) or with $(1 \mathrm{lanes}$ $3,6,9,12)$ RNase preincubation or were reacted with terminal deoxytransferase and ${ }^{32}$ P $\mid$ ddATP $($ lanes $1,4,7,10)$. $(C)$ Fractions of a glycerol gradient (for details, see Materials and methods) were assayed for telomerase activity with the primers $d\left(G_{4} T_{2}\right)_{3}\left(l a n e s 1_{1-12}\right.$ and $d\left(G_{3} T_{2} G\right)_{3}$ (lanes 13-18) in reactions with $\left[{ }^{32} \mathrm{P}\right] \mathrm{dGTP}$ and either TTP (lanes 1-6) or ddTTP (lanes 7-18). Reactions were stopped after $60 \mathrm{~min}$ and electrophoresed on an $8 \%$ gel. Fractions $18-28$ of a total of 40 fractions contained detectable telomerase activity, with the peak in short product DNA synthesis at fraction 24 . The ratio of short product DNAs from a given primer remains constant across fractions of the gradient but may differ from the ratios observed in other figures, which is probably attributable to the difference in enzyme preparation added to the reaction.

which occurred with a lower $K_{\mathrm{m}}$ of primer activation (10-50 nM; not shown, but see Fig. 2A). One possible explanation for the difference is that primer concentration influences primer alignment with the template (see Discussion). Time courses of accumulation of the 18and 22-residue products of $d\left(G_{3} T_{2} G\right)_{3}$ in the presence of $\left[{ }^{32} \mathrm{P}\right] \mathrm{dGTP}$ and ddTTP indicated that each product accumulated at a similar rate, with no lag in synthesis of the primer-sized product relative to longer product DNAs (not shown). This suggests that the primer-sized product was not generated from other telomerase elongation products or by cleavage of primer DNA before association with telomerase.

We hypothesized that a nucleolytic cleavage reaction was catalyzed by Tetrahymena telomerase, specific for or enhanced by binding of primer $3^{\prime}$ ends at a unique template position. We reasoned that the binding of $\mathrm{d}\left(\mathrm{G}_{3} \mathrm{~T}_{2} \mathrm{G}\right)_{3}$ to telomerase could result initially in removal of the primer $3^{\prime}$ dGMP residue. Addition of a ${ }^{32} \mathrm{P}$-labeled deoxyguanosine nucleotide to the shortened $d\left(G_{3} T_{2} G\right)_{3}$ primer would complete the synthesis of a primer-sized, radiolabeled $\mathrm{d}\left(\mathrm{G}_{3} \mathrm{~T}_{2} \mathrm{G}\right)_{3}$ product.

\section{Cleavage of previously added dGTP}

Because telomerase reacts only a very small percentage of primer molecules (not shown), the shortened product from cleavage reactions with $3^{\prime}$ - or $5^{\prime}$-end-labeled primers would be undetectable in the presence of the much greater amount of input primer. Instead of end-labeling the total primer population, we used telomerase to $3^{\prime}$ end-label a small amount of primer that would remain bound to the enzyme. The primer $\mathrm{pBRG}_{4} \mathrm{~T}_{2}$ /a chimera of pBR sequence and one telomeric repeat; see Fig. 3 legend for primer sequence) was elongated by $\leqslant 4 \mathrm{dGTP}$ and 1 ddTTP nucleotide in the presence of $\left[{ }^{32} \mathrm{P}\right] \mathrm{dGTP}$ and ddTTP (Fig. 3A). The amount of product elongated by 4 dGTP and 1 ddTTP nucleotide accumulated initially and then remained constant for $\geqslant 60 \mathrm{~min}$. The predominant product of the reaction, resulting from addition of a single ${ }^{32}$ P-labeled deoxyguanosine, also initially accumulated. However, this product DNA, as well as the product with one additional nucleotide added, subsequently disappeared with time (Fig. 3A). If these products were degraded from the $5^{\prime}$ end or internal sites, radiolabeled DNA products smaller than primer +1 nucleotide would be generated in the reaction. No such products were observed. This suggests that radiolabeled 3 ' residues were cleaved from the product DNA.

If cleavage of the $p B R G_{4} T_{2} G$ product $3^{\prime}$ residue was catalyzed by telomerase, addition of RNase might inhibit the cleavage reaction. Elongation reactions in the 


\section{A}

Primer

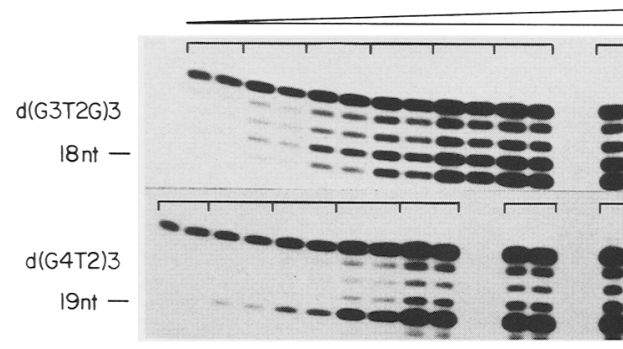

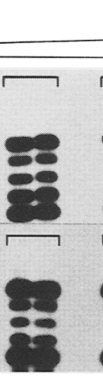

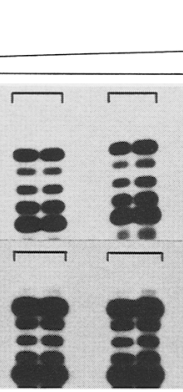

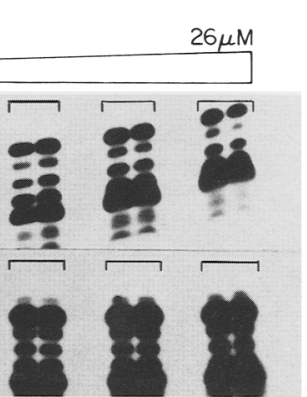

B

Figure 2. Primer concentration dependence of product synthesis. Reactions were performed for 50 min as described, and product DNA was precipitated, separated by PAGE on an $8 \%$ gel, subjected to autoradiography, and quantitated by PhosphorImager analysis (for details, see Materials and methods). (A) Autoradiograph of products of telomerase reactions in ${ }^{32} \mathrm{P} \mid \mathrm{dGTP}$ and ddTTP with the primers $\mathrm{d}\left(\mathrm{G}_{3} \mathrm{~T}_{2} \mathrm{G}\right)_{3}($ top $)$ and $\mathrm{d}\left(\mathrm{G}_{4} \mathrm{~T}_{2}\right)_{3}$ (bottom). For each primer, products from duplicate reactions at primer concentrations of 12.5, $25,50,100,200,400,800 \mathrm{nM}$ and 1.6, 3.2, 6.4, 12.8, and $26 \mu \mathrm{M}$ are shown, with primer concentration increasing to the right. At higher primer concentrations, products from reactions with different primer concentrations are separated by blank gel lanes to allow accurate quantitation. The migration of 18 - or 19- residue product DNA is indicated for both primers (18 nt and $19 \mathrm{nt})$. (B) The amount of 18-residue product DNA for the primer $\mathrm{d}\left(\mathrm{G}_{3} \mathrm{~T}_{2} \mathrm{G}\right)_{3}$ and 19-residue product DNA for the primer $\mathrm{d}\left(\mathrm{G}_{4} \mathrm{~T}_{2}\right)_{3}$ from the reactions in $A$ was quantitated by PhosphorImager analysis. A double-reciprocal plot of primer concentration (scale of $1 / \mu \mathrm{M}$ ) vs. product synthesis [scale of 1 /arbitrary unit of signal intensity; reactions of $d\left(G_{3} T_{2} G\right)_{3}$ and $d\left(G_{4} T_{2}\right)_{3}$ were quantitated on separate PhosphorImager screens and, thus, relative amounts of product synthesis between the two primers are not comparable] for primer concentrations between $100 \mathrm{nM}$ and $3.2 \mu \mathrm{M}$ indicates a $K_{\mathrm{m}}$ (negative inverse of the $\mathrm{x}$-axis intercept of fit shown) of $1.5 \mu \mathrm{M}$ for synthesis of both the 18-residue product of $d\left(G_{3} T_{2} G\right)_{3}(O)$ and the 19-residue product of $d\left(G_{4} T_{2}\right)_{3}(\square)$.

presence of $\left[{ }^{32} \mathrm{P}\right] \mathrm{dGTP}$ and ddTTP with either 200 or 800 $\mathrm{nM} \mathrm{pBRG}_{4} \mathrm{~T}_{2}$ were divided in half after $20 \mathrm{~min}$, and RNase was added to half of each reaction. Examination of product DNA in these reactions, at times before and after RNase addition, indicated that cleavage of the radiolabeled residues from the product DNA was inhibited by RNase (Fig. 3B). In the absence of RNase, cleavage was detectable within $20 \mathrm{~min}$ in the presence of $200 \mathrm{nM}$ primer and within $30 \mathrm{~min}$ in the presence of $800 \mathrm{nM}$ primer. The observed inhibition of cleavage by RNase was not attributable to protection of product DNA by factors released during RNase treatment: Pretreatment of extract with RNase had no effect on the degradation of $3{ }^{\prime}$ - or $5^{\prime}$-end-labeled primers by exogenously added micrococcal nuclease (not shown). In summary, the experiments described above indicate that telomerase removed
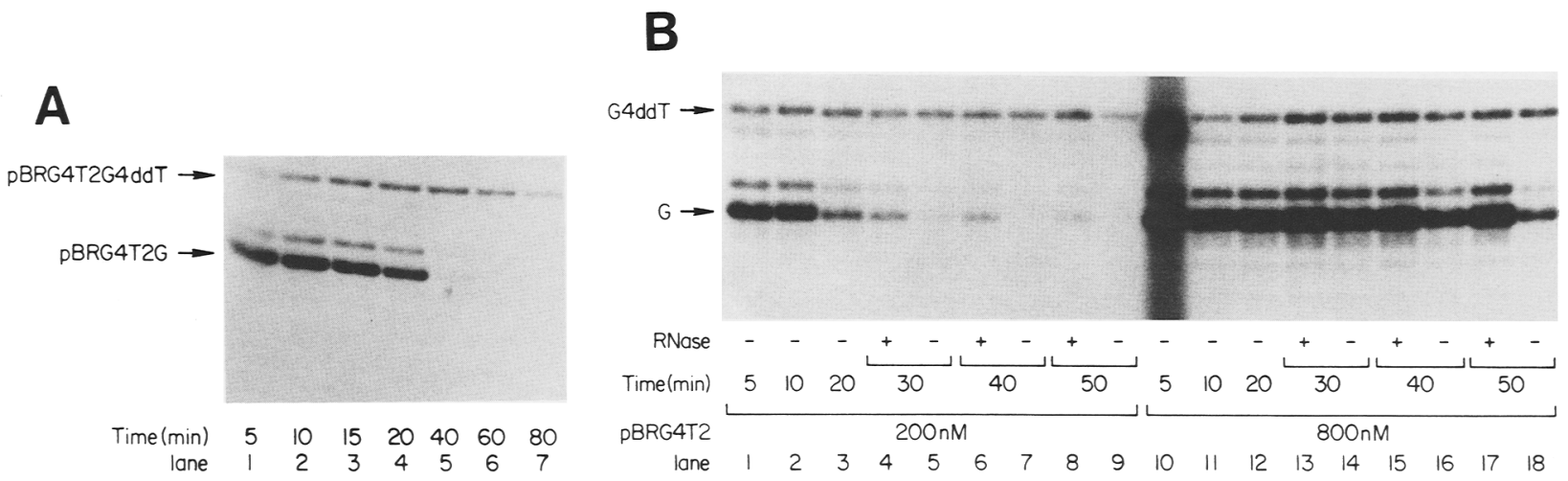

Figure 3. RNase sensitivity of the cleavage reaction. $(A)$ Aliquots of a telomerase elongation reaction in the presence of $200 \mathrm{nM}$ $\mathrm{pBRG}_{4} \mathrm{~T}_{2}\left(5^{\prime}\right.$-d(AGCCACTATCGACTACGCGGGGTT)-3'), [ $\left.{ }^{32} \mathrm{P}\right] \mathrm{dGTP}$, and ddTTP were removed and product DNA precipitated at increasing times $\left(5,10,15,20,40,60\right.$, or 80 min after initiation; lanes $1-7$, respectively). The migration of products of pBRG $\mathrm{T}_{2}$ is indicated at left by the product sequence. $(B)$ Telomerase elongation reactions of $\mathrm{pBRG}_{4} \mathrm{~T}_{2}$ in $\left[{ }^{32} \mathrm{P}\right] \mathrm{dGTP}$ and ddTTP at either $200 \mathrm{nM}$ (lanes 1-9) or $800 \mathrm{nM}$ (lanes 10-18) primer concentration were split immediately after the 20-min time point, and RNase was added to half of each reaction. Equal volume aliquots were removed at times before the splitting of the reaction $(5,10$, and $20 \mathrm{~min})$ or from both halves of the reaction after splitting $(30,40$, and $50 \mathrm{~min})$ as indicated, with RNase added (lanes $4,6,8,13,15,17)$ or nothing added (lanes $5,7,9,14,16,18$ ) to the reactions after splitting. Product DNA was precipitated and subject to PAGE and autoradiography. The migration of products of $\mathrm{pBRG}_{4} \mathrm{~T}_{2}$ is indicated at left as the sequence added to the primer. 
${ }^{32} \mathrm{P}$-labeled deoxyguanosine nucleotides added previously to the $3^{\prime}$ end of $\mathrm{pBRG}_{4} \mathrm{~T}_{2}$. Cleavage occurred at the same telomeric repeat position as the removal of the $3^{\prime}$ deoxyguanosine nucleotide of the primer $d\left(G_{3} T_{2} G\right)_{3}$.

\section{Primer sequence requirements of the cleavage reaction}

To determine whether nucleotides other than deoxyguanosine could be removed from a primer 3 ' end by telomerase, the primers $d\left(G_{3} T_{2} G\right)_{2} G_{3} T_{3}$ and $d\left(G_{3} T_{2} G_{2} G_{3} T_{2} A\right.$ were reacted with telomerase, $\left[{ }^{32} \mathrm{P}\right] \mathrm{dGTP}$, and ddTTP or TTP (Fig. 4A). The substitution of thymidine (lanes 2,3 ) or deoxyadenosine (lanes 5,6$)$ for deoxyguanosine at the $3^{\prime}$ end of the cleaved primer $\mathrm{d}\left(\mathrm{G}_{3} \mathrm{~T}_{2} \mathrm{G}\right)_{3}$ resulted in the synthesis of primer-sized and longer products, in the presence of either ddTTP (lanes 2,5) or TTP (lanes 3,6). Thus, telomerase was able to cleave thymidine or deoxyadenosine from a primer $3^{\prime}$ end. In the presence of ddTTP, both primers stimulated synthesis of six products rather than the expected maximum of five. Telomerase can elongate primer $3^{\prime}$ ends that are mismatched with the RNA template sequence (e.g., see Harrington and Greider 1991). Thus, the six products of each primer in reactions with ddTTP most likely resulted from alternate recognition of the primer $3^{\prime}$ ends by telomerase, allowing either cleavage and incorporation of 5 nucleotides (a maximum product length of primer +4 nucleotides) or incorporation of 5 nucleotides without cleavage (maximum product length of primer +5 nucleotides).

To test whether the $d\left(G_{3} T_{2} G\right)_{3}$ permutation of the telomeric repeat present at either the primer $5^{\prime}$ or $3^{\prime}$ end alone was sufficient to stimulate the cleavage reaction, primers corresponding to $d\left(G_{3} T_{2} G\right)_{3}$ with 2 extra residues at either the $3^{\prime}$ or $5^{\prime}$ end were reacted with telomerase, $\left[{ }^{32} \mathrm{P}\right] \mathrm{dGTP}$, and ddTTP or TTP (Fig. 4B). In the presence of ddTTP, the primer $d\left(G_{3} T_{2} G_{3} G_{2}\right.$ was elongated by $\leqslant 1 \mathrm{dGTP}$ and 1 ddTTP nucleotide, with little or no synthesis of a 20-residue, primer-sized product DNA in the presence of ddTTP (lane 11) or TTP (lane 12). Elongation of the primer $\mathrm{dG}_{2}\left(\mathrm{G}_{3} \mathrm{~T}_{2} \mathrm{G}\right)_{3}$ in the presence of ddTTP (lane 14) or TTP (lane 15) did result in synthesis of primer-sized product DNA, as well as incorporation of $\leqslant 3$ dGTP and 1 ddTTP nucleotide in the presence of ddTTP (lane 14). In the presence of TTP, the primer $\mathrm{dG}_{2}\left(\mathrm{G}_{3} \mathrm{~T}_{2} \mathrm{G}\right)_{3}$ generated a ladder of product DNA with the most intense products in a 6-residue repeat beginning at primer $+5 / 6$ residues (lane 15 ). These predominant products correspond to incorporation of the first dGTP and usually, to a lesser extent, the second TTP of the sequence $\mathrm{dT}_{2} \mathrm{G}_{4}$, determined by elongation of primers with different $3^{\prime}$ ends and by reaction of primers in dideoxynucleotides (Greider and Blackburn 1987; Greider 1991b). Thus, the ladder of product DNA intensities can suggest an alignment of the primer $3^{\prime}$ end with the template sequence. The elongation of $d^{2} G_{2}\left(G_{3} T_{2} G\right)_{3}$ was similar to elongation of $d\left(G_{3} T_{2} G\right)_{3}$, which also generated intense products beginning at primer $+5 / 6$ residues in the presence of TTP and products elongated by $\leqslant 4 \mathrm{nu}-$ cleotides in the presence of ddTTP (lanes 5,6 ). Thus, the $3^{\prime}$ ends of these primers share a favored alignment with the template RNA. In comparison, for reactions in the presence of TTP, the primer $d\left(G_{4} T_{2}\right)_{3}$ generated intense products beginning at primer $+6 / 7$ residues (lane 3 ), and the primer $\mathrm{d}\left(\mathrm{GT}_{2} \mathrm{G}_{3}\right)_{3}$ generated intense products beginning at primer $+3 / 4$ residues (lane 9). These primers were correspondingly elongated by $\leqslant 5$ or $\leqslant 3$ nucleotides, respectively, in the presence of ddTTP (lanes $2,8)$.

To determine whether a short sequence of the correct permutation at the primer 3 ' end was sufficient to stimulate the cleavage reaction, the primers $d(T G)_{9}$ and $\mathrm{d}(\mathrm{TG})_{8} \mathrm{~T}_{2} \mathrm{G}$ were reacted with telomerase, $\left[{ }^{32} \mathrm{P}\right] \mathrm{dGTP}$, and ddTTP or TTP (Fig. 4B). In the presence of TTP, these primers generated ladders of product DNA as expected if aligned with a template RNA sequence $3^{\prime}$ (A)AC-5' at their $3^{\prime}$ ends [predominant products beginning at primer $+5 / 6$ residues (Fig. $4 \mathrm{~B}$, lanes 18,21 ); see also d(TG) $)_{9}$ in Blackburn et al. (1989)]. This alignment was also observed with ddTTP, in the presence of which both primers were elongated by $\leqslant 3 \mathrm{dGTP}$ and 1 ddTTP nucleotide (lanes 17,20). Although these primers shared the template alignment and either the 2 or 4 residues at the 3' end of $d\left(G_{3} T_{2} G\right)_{3}$, no cleavage was observed (lanes 16-21, 25-27). Thus, cleavage occurred if a $3^{\prime}$ deoxyguanosine nucleotide followed the primer sequence $\mathrm{dG}_{4} \mathrm{~T}_{2}$ (as in $\mathrm{pBRG}_{4} \mathrm{~T}_{2}$; see Fig. 3), but not if a $3^{\prime}$ deoxyguanosine nucleotide followed only a partial repeat of $\mathrm{dG}_{4} \mathrm{~T}_{2}$ sequence.

We then determined whether residues inserted or deleted between the $3^{\prime}$ primer nucleotide and the rest of the primer $d\left(G_{3} T_{2} G\right)_{3}$ sequence affected the cleavage reaction. Reaction of the primer $d\left(G_{3} T_{2} G_{2}\right)_{3} T_{3} G$ with telomerase, $\left[{ }^{32} \mathrm{P}\right] \mathrm{dGTP}$, and ddTTP generated cleavage products of primer size and 1 residue shorter than the primer, as well as 4 products longer than the primer, corresponding to incorporation of $\leqslant 3 \mathrm{dGTP}$ and 1 ddTTP nucleotide (Fig. 4C, lane 1). Reaction of the primer $\mathrm{d}\left(\mathrm{G}_{3} \mathrm{~T}_{2} \mathrm{G}\right)_{2} \mathrm{G}_{3} \mathrm{TG}$ with telomerase under the same conditions resulted in incorporation of $\leqslant 3 \mathrm{dGTP}$ and 1 ddTTP nucleotide but no synthesis of primer-sized product DNA (lane 3). Both d $\left(\mathrm{G}_{3} \mathrm{~T}_{2} \mathrm{G}\right)_{2} \mathrm{G}_{3} \mathrm{~T}_{3} \mathrm{G}$ and $\mathrm{d}\left(\mathrm{G}_{3} \mathrm{~T}_{2} \mathrm{G}\right)_{2} \mathrm{G}_{3} \mathrm{TG}$ promoted synthesis of a greatly reduced amount of product DNA in the presence of TTP relative to telomeric repeat primers (not shown).

Although the cleavage reaction was not specific for removal of template-complementary nucleotides, nucleotide addition to cleaved primers incorporated only correctly templated nucleotides. Neither primer $d\left(G_{3} T_{2} G\right)_{3}$ nor primer $d\left(G_{3} T_{2} G\right)_{2} G_{3} T G$, which might be expected to incorporate a TTP nucleotide initially if the $3^{\prime}$ deoxyguanosine was removed, were labeled in telomerase reactions with ${ }^{32} \mathrm{P} \mid \mathrm{TTP}$ alone or in the presence of ddGTP (Fig. 4D, lanes 4-7). In contrast, the primer $\mathrm{d}\left(\mathrm{T}_{2} \mathrm{G}_{4}\right)_{3}$ was elongated by $\leqslant 2$ TTP nucleotides with $\left[{ }^{32} \mathrm{P}\right] \mathrm{TTP}$ or 2 TTP and 1 ddGTP nucleotide with $\left[{ }^{32}\right.$ P]TTP and ddGTP (Fig. 4D, lanes 2,3). A ladder of product DNA was observed if dGTP was added to ${ }^{32} \mathrm{P} \mid \mathrm{TTP}$ reactions (not shown). 

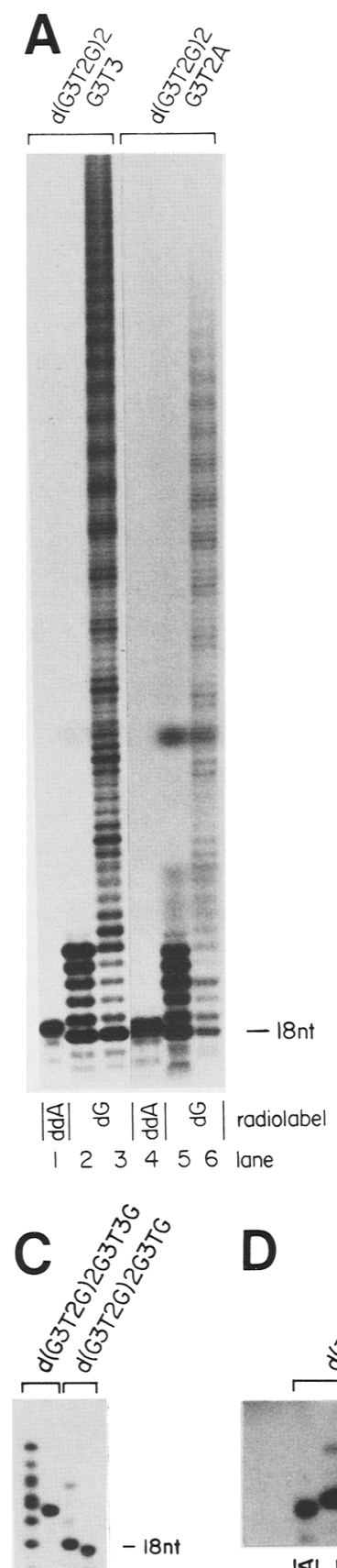

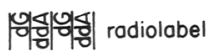
1234 lone

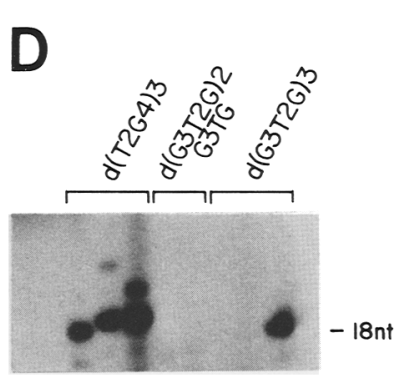

$\mid$ 部 $\vdash|\vdash| \vdash\left|\frac{8}{8}\right|$ radiolabe I 2345678 lane

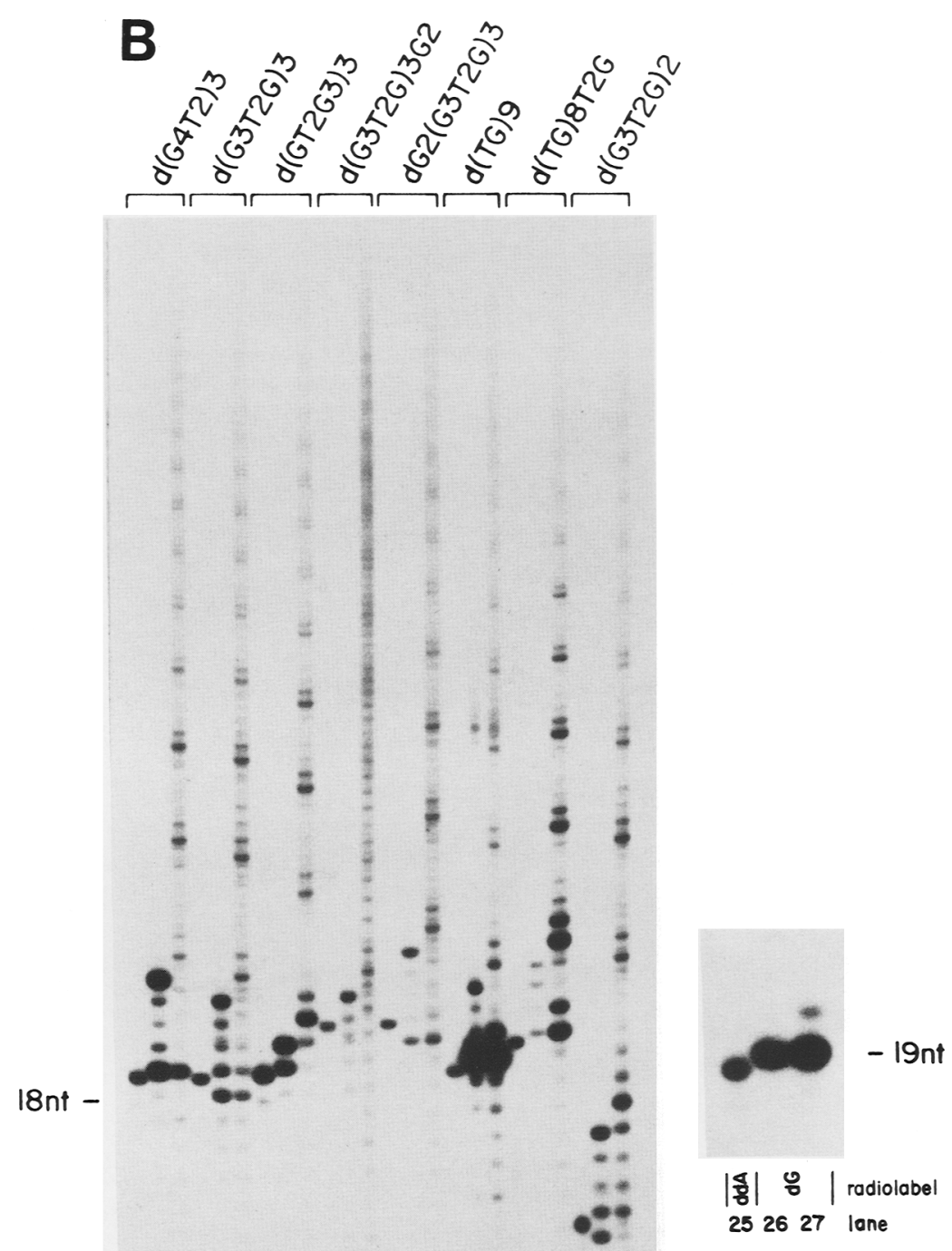

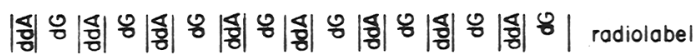
| $2345678910 \mid 112131415161718192021222324$ lane

Figure 4. Primer specificity of the cleavage reaction. Reactions were performed as described, and product DNA was precipitated, separated by PAGE, and subject to autoradiography (for details, see Materials and methods). The migration of an 18- or 19-residue product DNA is indicated (18 $\mathrm{nt}$ and $19 \mathrm{nt}) .(A)$ The primers $\mathrm{d}\left(\mathrm{G}_{3} \mathrm{~T}_{2} \mathrm{G}\right)_{2} \mathrm{G}_{3} \mathrm{~T}_{3}$ (lanes 1-3) and $\mathrm{d}\left(\mathrm{G}_{3} \mathrm{~T}_{2} \mathrm{G}\right)_{2} \mathrm{G}_{3} \mathrm{~T}_{2} \mathrm{~A}$ (lanes 4-6) were reacted with terminal deoxytransferase and $\left.{ }^{32} \mathrm{P}\right] \mathrm{ddATP}$ (lanes 1,4 ) or with telomerase, $\left[{ }^{32} \mathrm{P}\right] \mathrm{dGTP}$, and either ddTTP (lanes 2,5 ) or TTP (lanes 3,6 ). The intensity of products in lanes $4-6$ represents $\sim 400 \%$ exposure time of the products in lanes 1-3. (B) The primers $\mathrm{d}\left(\mathrm{G}_{4} \mathrm{~T}_{2}\right)_{3}$ (lanes 1-3), $\mathrm{d}\left(\mathrm{G}_{3} \mathrm{~T}_{2} \mathrm{G}\right)_{3}$ (lanes 4-6), $\mathrm{d}\left(\mathrm{GT}_{2} \mathrm{G}_{3}\right)_{3}$ (lanes 7-9), $d\left(\mathrm{G}_{3} \mathrm{~T}_{2} \mathrm{G}\right)_{3} \mathrm{G}_{2}$ (lanes 10-12), $\mathrm{dG}_{2}\left(\mathrm{G}_{3} \mathrm{~T}_{2} \mathrm{G}\right)_{3}$ (lanes 13-15), d(TG) (lanes 16-18), d(TG $)_{8} \mathrm{~T}_{2} \mathrm{G}$ (lanes 19-21), and $\mathrm{d}\left(\mathrm{G}_{3} \mathrm{~T}_{2} \mathrm{G}\right)_{2}$ (lanes 22-24) were reacted with terminal deoxytransferase and $\left[{ }^{32} \mathrm{P}\right] \mathrm{ddATP}$ (lanes $1,4,7,10,13,16,19,22$ ) or with telomerase, $\left[{ }^{32} \mathrm{P}\right] \mathrm{dGTP}$, and either ddTTP (lanes $2,5,8,11,14,17,20,23$ ) or TTP $($ lanes $3,6,9,12,15,18,21,24)$. The primer $\mathrm{d}(\mathrm{TG})_{9}$ contains a minor contaminant that generated the $\sim 50$-residue product visible in lane 17 . Lanes $25-27$ are a shorter exposure of the intense products in lanes 16-18. $(C)$ The primers $d\left(G_{3} T_{2} G\right)_{2} G_{3} T_{3} G$ (lanes 1,2$)$ and $d\left(G_{3} T_{2} G\right)_{2} G_{3} T G(l a n e s 3,4)$ were reacted with telomerase, $\left[{ }^{32} \mathrm{P}\right] \mathrm{dGTP}$, and ddTTP (lanes 1,3$)$ or with terminal deoxytransferase and $\left[{ }^{32} \mathrm{P}\right] \mathrm{ddATP}(\mathrm{lanes} 2,4)$. $(D)$ The primers $\mathrm{d}\left(\mathrm{T}_{2} \mathrm{G}_{4}\right)_{3}$ (lanes 1-3), $\mathrm{d}\left(\mathrm{G}_{3} \mathrm{~T}_{2} \mathrm{G}_{2} \mathrm{G}_{3} \mathrm{TG}\right.$ (lanes 4-5), and $\mathrm{d}\left(\mathrm{G}_{3} \mathrm{~T}_{2} \mathrm{G}\right)_{3}$ (lanes 6-8) were reacted with terminal deoxytransferase and $\left[{ }^{32} \mathrm{P}\right.$ )ddATP (lanes 1,8$)$ or with telomerase and either $\left[{ }^{32} \mathrm{P}\right] \mathrm{TTP}$ and ddGTP (lanes $\left.2,4,6\right)$ or $\left[{ }^{32} \mathrm{P}\right] \mathrm{TTP}$ alone $($ lanes $3,5,7)$. 
Primers of $<10$ residues are nonprocessively elongated and are not cleaved

We tested the primer length dependence of the telomerase cleavage reaction. The 12-residue primer $\mathrm{d}\left(\mathrm{G}_{3} \mathrm{~T}_{2} \mathrm{G}\right)_{2}$ was cleaved to generate primer-sized product DNA when reacted with telomerase, $\left[{ }^{32} \mathrm{P}\right] \mathrm{dGTP}$, and ddTTP or TTP, although more cleavage was observed in the presence of ddTTP than in the presence of TTP (Fig. 4B, lanes 23,24). To investigate the cleavage and elongation of primers shorter than 12 residues, we assayed telomerase reaction products of the primers $\mathrm{dG}_{4} \mathrm{~T}_{2} \mathrm{G}, \mathrm{dG}_{4} \mathrm{~T}_{2}, \mathrm{dT}_{2} \mathrm{G}_{4}$, $\mathrm{dT}_{2} \mathrm{G}_{4} \mathrm{~T}_{2}$, and $\mathrm{dG}_{4} \mathrm{~T}_{2} \mathrm{G}_{4}$. Although previous reports suggested that primers of only one telomeric repeat were not elongated by Tetrahymena telomerase (Greider and Blackburn 1987), we observed that all of the above primers were elongated by our more purified telomerase preparation, most efficiently at higher primer concentrations than previously tested. In contrast with longer telomeric repeat primers, however, the processivity of elongation for primers $<10$ residues in length was dramatically influenced by primer concentration (Fig. 5A). Telomeric repeat primers of $<10$ residues stimulated some processive elongation, but much more product DNA was synthesized at $>1-5 \mu \mathrm{M}$ primer concentration by the addition of one partial repeat to each primer (lanes 9-24). As primer concentration increased, the proportion of product DNA elongated by only one repeat increased. In contrast, the 10-residue primer $\mathrm{dG}_{4} \mathrm{~T}_{2} \mathrm{G}_{4}$ was elongated processively at all primer concentrations between $12.5 \mathrm{nM}$ and $51 \mu \mathrm{M}$ (lanes 5-8), typical of telomeric repeat primers of $\geqslant 10$ residues. The amount of product DNA in reactions of $\mathrm{dG}_{4} \mathrm{~T}_{2} \mathrm{G}_{4}$ increased as primer concentration increased, but no change in the relative amounts of different length products was observed. A third class of primers, nontelomeric repeat primers such as $d(T G)_{8} T_{2} G$, were elongated processively at low primer concentration, but products from the addition of a single repeat
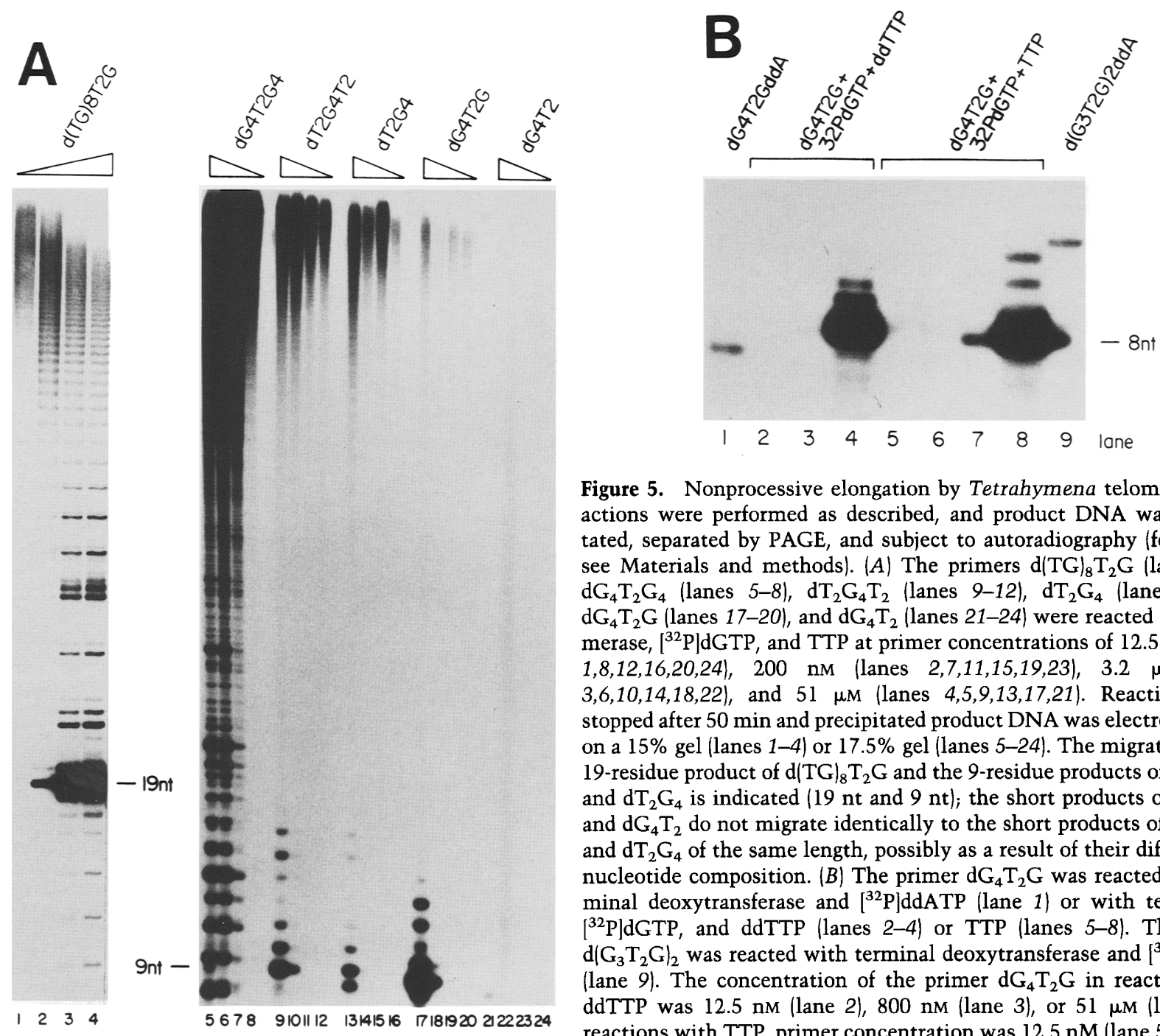

Figure 5. Nonprocessive elongation by Tetrahymena telomerase. Reactions were performed as described, and product DNA was precipitated, separated by PAGE, and subject to autoradiography (for details, see Materials and methods). (A) The primers $d(T G)_{8} T_{2} G$ (lanes 1-4), $\mathrm{dG}_{4} \mathrm{~T}_{2} \mathrm{G}_{4}$ (lanes 5-8), dT $\mathrm{d}_{2} \mathrm{G}_{4} \mathrm{~T}_{2}$ (lanes 9-12), $\mathrm{dT}_{2} \mathrm{G}_{4}$ (lanes 13-16), $\mathrm{dG}_{4} \mathrm{~T}_{2} \mathrm{G}$ (lanes 17-20), and $\mathrm{dG}_{4} \mathrm{~T}_{2}$ (lanes 21-24) were reacted with telomerase, $\left[{ }^{32} \mathrm{P}\right] \mathrm{dGTP}$, and TTP at primer concentrations of $12.5 \mathrm{nM}$ (lanes $1,8,12,16,20,24$ ), $200 \mathrm{nM}$ (lanes 2,7,11,15,19,23), $3.2 \mu \mathrm{M}$ (lanes $3,6,10,14,18,22$ ), and $51 \mu \mathrm{M}$ (lanes $4,5,9,13,17,21$ ). Reactions were stopped after $50 \mathrm{~min}$ and precipitated product DNA was electrophoresed on a $15 \%$ gel (lanes $1-4)$ or $17.5 \%$ gel (lanes $5-24)$. The migration of the 19-residue product of $d(T G)_{8} T_{2} G$ and the 9-residue products of $\mathrm{dT}_{2} \mathrm{G}_{4} \mathrm{~T}_{2}$ and $\mathrm{dT}_{2} \mathrm{G}_{4}$ is indicated ( $19 \mathrm{nt}$ and $9 \mathrm{nt}$ ); the short products of $\mathrm{dG}_{4} \mathrm{~T}_{2} \mathrm{G}$ and $d_{4} \mathrm{~T}_{2}$ do not migrate identically to the short products of $\mathrm{dT}_{2} \mathrm{G}_{4} \mathrm{~T}_{2}$ and $\mathrm{dT}_{2} \mathrm{G}_{4}$ of the same length, possibly as a result of their difference in nucleotide composition. $(B)$ The primer $\mathrm{dG}_{4} \mathrm{~T}_{2} \mathrm{G}$ was reacted with terminal deoxytransferase and $\left[{ }^{32} \mathrm{P}\right] \mathrm{ddATP}$ (lane 1) or with telomerase, $\left.{ }^{32} \mathrm{P}\right] \mathrm{dGTP}$, and ddTTP (lanes 2-4) or TTP (lanes 5-8). The primer $\mathrm{d}\left(\mathrm{G}_{3} \mathrm{~T}_{2} \mathrm{G}\right)_{2}$ was reacted with terminal deoxytransferase and $\left[{ }^{32} \mathrm{P}\right] \mathrm{ddATP}$ (lane 9). The concentration of the primer $d_{G_{4}} T_{2} G$ in reactions with ddTTP was $12.5 \mathrm{nM}$ (lane 2), $800 \mathrm{nM}$ (lane 3), or $51 \mu \mathrm{M}$ (lane 4). In reactions with TTP, primer concentration was $12.5 \mathrm{nM}$ (lane 5), $200 \mathrm{nM}$ (lane 6), 3.2 $\mu \mathrm{M}$ (lane 7), or $51 \mu \mathrm{M}$ (lane 8). Telomerase reactions were stopped after $50 \mathrm{~min}$, and product DNAs were electrophoresed on a $15 \%$ gel. The migration of the 8 -residue product of $\mathrm{dG}_{4} \mathrm{~T}_{2} \mathrm{G}$ is indicated $(8 \mathrm{nt})$. 
increased relative to longer products at high primer concentration (lanes 1-4). Thus, for short telomeric repeat primers and for deoxyguaosine-rich, nontelomeric repeat primers, high primer concentration resulted in nonprocessive synthesis; only one telomeric repeat was added to primer DNA.

Although the $3^{\prime}$ nucleotide of $\mathrm{pBRG}_{4} \mathrm{~T}_{2} \mathrm{G}$ was cleaved by telomerase (see Fig. 3), the $3^{\prime}$ nucleotide of the primer $\mathrm{dG}_{4} \mathrm{~T}_{2} \mathrm{G}$ was not (Fig. $5 \mathrm{~B}$ ). Reaction of $\mathrm{dG}_{4} \mathrm{~T}_{2} \mathrm{G}$ with telomerase, $\left[{ }^{32} \mathrm{P}\right] \mathrm{dGTP}$, and ddTTP (lanes 2-4) or TTP (lanes 5-8) at concentrations ranging from $12.5 \mathrm{nM}$ (lanes $2,5)$ to $51 \mu \mathrm{M}($ lanes 4,8$)$ did not generate a detectable level of a primer-sized, radiolabeled product DNA. The primer $\mathrm{dG}_{4} \mathrm{~T}_{2} \mathrm{G}$ was elongated by $\leqslant 4$ nucleotides in the presence of ddTTP, corresponding to incorporation of 3 dGTP and 1 ddTTP nucleotide. In the presence of TTP, efficient synthesis to the end of the template was not observed; instead, products of incorporation of only $\leqslant 5$ nucleotides predominated, corresponding to incorporation of $\leqslant 3 \mathrm{dGTP}$ and 2 TTP nucleotides. The failure of this primer to stimulate efficient elongation to the end of the template was unique among the short primers assayed in Figure 5A. The primers $\mathrm{dG}_{4} \mathrm{~T}_{2}, \mathrm{dT}_{2} \mathrm{G}_{4}$, and $\mathrm{dT}_{2} \mathrm{G}_{4} \mathrm{~T}_{2}$ were elongated efficiently to the end of the template by incorporation of $1 \mathrm{dGTP}, 2 \mathrm{TTP}+1 \mathrm{dGTP}$, or $1 \mathrm{dGTP}$, respectively, as determined by reactions of these primers with telomerase in the presence of $\left.{ }^{32} \mathrm{P}\right]$ TTP or $\left[{ }^{32} \mathrm{P}\right] \mathrm{dGTP}$ alone or with deoxynucleotides or dideoxynucleotides (not shown; see predominant short products in Fig. 5A).

\section{Discussion}

To understand the range of possible functions of telomerase in vivo, we analyzed the biochemical activities of Tetrahymena telomerase in vitro. We describe several activities catalyzed by telomerase, including a $3^{\prime} \rightarrow 5^{\prime}$ nucleolytic cleavage activity and a nonprocessive mode of elongation. These activities suggest additional functions for telomerase in vivo and also suggest mechanisms of product binding, cleavage, and elongation for telomerase that are similar to other polymerase enzymes.

\section{The nucleolytic cleavage reaction}

The primer specificities of the cleavage reaction suggest that cleavage occurs if the primer or product $3^{\prime}$ end is aligned with the cytosine residue at the extreme $5^{\prime}$ end of the template RNA sequence, the last template position for nucleotide addition before repositioning of the product $3^{\prime}$ end (as underlined: $3^{\prime}$-AACCCCAAC- $5^{\prime}$ ). The nucleolytic cleavage reaction required substrates with a complete telomeric repeat of permutation $\mathrm{dG}_{3} \mathrm{~T}_{2} \mathrm{G}$ at the $3^{\prime}$ end, which would allow a primer or product $3^{\prime}$ end to be positioned at the $5^{\prime}$ end of the template. For example, substrates $d\left(G_{3} T_{2} G\right)_{3}, d_{2}\left(G_{3} T_{2} G\right)_{3}$, and $p^{2} R_{4} T_{2} G$ were cleaved, but no cleavage of $d(T G)_{9}, d(T G)_{8} T_{2} G$, or $\mathrm{d}\left(\mathrm{G}_{3} \mathrm{~T}_{2} \mathrm{G}\right)_{2} \mathrm{G}_{3} \mathrm{TG}$ was observed. Also, although $\mathrm{d}\left(\mathrm{G}_{3} \mathrm{~T}_{2}\right.$ $\mathrm{G})_{2} \mathrm{G}_{3} \mathrm{TG}$ was not cleaved, $\mathrm{d}\left(\mathrm{G}_{3} \mathrm{~T}_{2} \mathrm{G}\right)_{2} \mathrm{G}_{3} \mathrm{~T}_{3} \mathrm{G}$ was appar- ently cleaved by 2 residues. If these two primers were aligned by binding of the most $3^{\prime} \mathrm{dT}_{2} \mathrm{G}_{4}$ primer repeat to the template, the $3^{\prime}$ end of $d\left(G_{3} T_{2} G_{2} G_{3} T G\right.$ would not extend to the $5^{\prime}$ cytosine of the template, whereas the $3^{\prime}$ end of $d\left(G_{3} T_{2} G\right)_{2} G_{3} T_{3} G$ would be extended an extra residue beyond this site. Efficient cleavage of $>1$ residue from primers composed of only telomeric repeats was not observed; correspondingly, the elongation products of telomeric repeat primers with $>1$ deoxyguanosine residue at the 3 ' end suggest alignment in the middle of the template sequence (see Fig. 1A). In contrast with other primers of $<10$ residues, $\mathrm{dG}_{4} \mathrm{~T}_{2} \mathrm{G}$ was elongated by $\leqslant 4-5$ nucleotides, generating products longer than the 9-residue template RNA sequence. The lack of cleavage of this primer is correlated with the apparent alignment of only its $3^{\prime} \mathrm{dT}_{2} \mathrm{G}$ sequence with the template, at the template $3^{\prime}$ end.

The primer concentration dependence of product synthesis analyzed in Figure 2 suggests that telomerase can catalyze at least two different deoxyguanosine addition reactions. The amount of primer-sized product of $\mathrm{d}\left(\mathrm{G}_{3} \mathrm{~T}_{2} \mathrm{G}\right)_{3}$ and primer +1 nucleotide product of $\mathrm{d}\left(\mathrm{G}_{4} \mathrm{~T}_{2}\right)_{3}$ increased relative to longer nucleotide addition products as primer concentration increased. The template RNA sequence indicates two possible template sites for addition of the first deoxyguanosine in a telomeric repeat: the extreme $5^{\prime}$ end of the template or toward the $3^{\prime}$ end of the template (as underlined: $3^{\prime}$-AACCCCAAC- $5^{\prime}$ or 3'-AACCCCAAC-5', respectively). The primer specificities of cleavage described above suggest that cleavage occurs at the extreme $5^{\prime}$ end of the template. We suggest that addition of a single deoxyguanosine to cleaved $\mathrm{d}\left(\mathrm{G}_{3} \mathrm{~T}_{2} \mathrm{G}\right)_{3}$ or to $\mathrm{d}\left(\mathrm{G}_{4} \mathrm{~T}_{2}\right)_{3}$ can occur at the $5^{\prime}$ end of the template, constituting the "single-nucleotide addition activity" assayed in Figure 2B. In contrast, the initial dGTP added to longer products of $d\left(G_{3} T_{2} G\right)_{3}$ and $\mathrm{d}\left(\mathrm{G}_{4} \mathrm{~T}_{2}\right)_{3}$ in the presence of ddTTP would be added predominantly with alignment of the primer $3^{\prime}$ end at the $3^{\prime}$ end of the template. Because the amount of product from single nucleotide addition increased relative to longer products with increasing primer concentration, binding of the primer $3^{\prime}$ end at the template $5^{\prime}$ end appears to be enhanced at high primer concentration. Thus, at least in vitro, increasing primer concentration favored cleavage over elongation. The distinct kinetics of the single nucleotide addition activity, with or without prior cleavage, would result from the requirement for repositioning of the product $3^{\prime}$ end to the $3^{\prime}$ end of the template before addition of another nucleotide.

\section{Elongation processivity}

The effects of primer length and concentration on the processivity of elongation suggest two sites of association of primer or product DNA with telomerase. In the presence of dGTP and TTP, the primers $\mathrm{dT}_{2} \mathrm{G}_{4}, \mathrm{dG}_{4} \mathrm{~T}_{2}$, and $\mathrm{dT}_{2} \mathrm{G}_{4} \mathrm{~T}_{2}$ appeared to align predominantly or entirely within the 9-nucleotide template RNA sequence. These primers were elongated by the number of residues expected for synthesis to the $5^{\prime}$ end of the template, given 
primer alignment within the template sequence. Release of product DNA from the template is required if telomerase is to repeatedly realign product DNA with, and recopy from, the short template region of the telomerase RNA. Thus, products from the elongation of short primers, if bound only to the RNA template, would dissociate from telomerase after synthesis of one partial repeat. Longer primers may be anchored to telomerase by association with a second site in addition to binding at the template site to prevent dissociation during product 3 'end repositioning. The high primer concentration required for efficient reaction of the short primers may result from a reduced affinity of binding to the template alone: $>10 \mu \mathrm{M}$ of a primer, such as $\mathrm{dT}_{2} \mathrm{G}_{4}$, was required to compete with synthesis primed by $25 \mathrm{nM} d\left(\mathrm{G}_{4} \mathrm{~T}_{2}\right)_{3}$ (not shown). The elongation of Tetrahymena telomeric repeat primers of $\geqslant 10$ residues by Tetrahymena telomerase was processive, independent of primer concentration. This differs from results obtained for elongation of human telomeric repeat primers by human telomerase, which appears to occur with primer concentration-dependent processivity for primers $\geqslant 10$ residues (Morin 1989).

\section{Model for primer binding, cleavage, and elongation by telomerase}

The effects of primer length, sequence, and concentration on the nucleolytic cleavage reaction and the processivity of elongation provide evidence for a detailed model of telomerase action (Fig. 6). To explain the results of primer length and concentration on processivity, as described above, we propose two distinct binding sites for primer or product DNA. One site, termed the template site, binds primer sequence complementary to the template. This site may correspond to the template region of the RNA itself, as envisioned in previous models (Greider and Blackburn 1989), or to a site formed by both protein and RNA components. We propose a second binding site termed the anchor site, which would bind residues $5^{\prime}$ of and adjacent to residues bound at the template site. This differs from previous models proposing additional sites for primer recognition on the basis of sequence or secondary structure (Blackburn et al. 1989; Morin 1989, 1991; Harrington and Greider 1991). Our data and model suggest that a 6-residue spacing of telomeric repeats may be critical for optimal primer binding at both template and anchor sites. Interestingly, alteration of the telomeric sequence repeat length, by insertion of an extra cytosine in the template sequence, did reduce the fidelity of template copying in vivo (Yu and Blackburn 1991).

After primer binding and elongation to the $5^{\prime}$ end of the template, repositioning of the product $3^{\prime}$ end can occur. This event, described previously as translocation, may occur before or after addition of a deoxyguanosine encoded by the most $5^{\prime}$ template cytosine residue. Incorporation of this dGTP would correspond to the kinetically distinct single-nucleotide addition activity described in this paper. Instead of repositioning, the $3^{\prime}$ end of a primer or of a product elongated to the template $5^{\prime}$ end can also undergo nucleotide removal or cleavage. Synthesis of another telomeric repeat begins when the product $3^{\prime}$ end is released from the $5^{\prime}$ end of the template site and re-establishes stable alignment with the $3^{\prime}$ end of the template. Processive elongation of $\mathrm{dG}_{4} \mathrm{~T}_{2} \mathrm{G}_{4}$ suggests that the sequence $\mathrm{dG}_{4}$ bound to the anchor site, $5^{\prime}$ to the $\mathrm{dT}_{2} \mathrm{G}_{4}$ sequence aligned with the template, is sufficient to prevent release of product DNA during product $3^{\prime}$-end repositioning. The sequence $\mathrm{dG}_{4}$ of the primer $\mathrm{dG}_{4} \mathrm{~T}_{2} \mathrm{G}$ may also bind to the anchor site because this primer, as with $\mathrm{dG}_{4} \mathrm{~T}_{2} \mathrm{G}_{4}$, was elongated by several nucleotides. Elongation of $\mathrm{dG}_{4} \mathrm{~T}_{2} \mathrm{G}$ was not processive, however, possibly the result of inefficient copying to the template $5^{\prime}$ end.

Sequences other than a telomeric repeat that become bound at the anchor site may have lower affinity for telomerase than a $\mathrm{dT}_{2} \mathrm{G}_{4}$ repeat. A switch in the processivity of synthesis was observed for nontelomeric repeat primers, such as $d(T G)_{8} T_{2} G$, with increasing primer concentration. A similar increase in proportion of short products with increased primer concentration was not observed for $\geqslant 10$-residue telomeric repeat primers. The probability of product dissociation from telomerase would increase at high primer concentration if competition for binding to the template site occurred between primer in solution and the product $3^{\prime}$ end. Products bound to the anchor site with sequence other than a telomeric repeat may be released preferentially under these conditions of competition. Interestingly, products from the addition of one partial repeat to $d(T G)_{8} T_{2} G$ increased with primer concentration more than products from the addition of many repeats. Replacement of the original anchor sequence by a newly synthesized $\mathrm{dT}_{2} \mathrm{G}_{4}$ repeat would increase the affinity of the product DNA for telomerase and allow processive synthesis of additional repeats even at high primer concentration. Replacement of the sequence bound at the anchor site would not decrease the processivity of elongation, if it occurred while the product remained bound at the template site. The release of product from only one site at a time could be accomplished either as a result of fast release and rebinding at the anchor site relative to synthesis of a repeat or as a result of energetically favorable dissociation only if product is bound at another site. This model for elongation by telomerase resembles a model for elongation by Escherichia coli RNA polymerase (Surratt et al. 1991). In both models the processivity of synthesis derives from the successive release and replacement of product bound at two single-stranded polynucleotide binding sites. Dissociation of a product would occur only with the low probability of simultaneous release from both sites.

\section{The cleavage activity catalyzed by telomerase resembles that of DNA-dependent RNA polymerases}

The $3^{\prime} \rightarrow 5^{\prime}$ nucleolytic cleavage reaction that we describe for telomerase bears interesting similarities to the cleavage reactions described previously for bacterial, eu- 


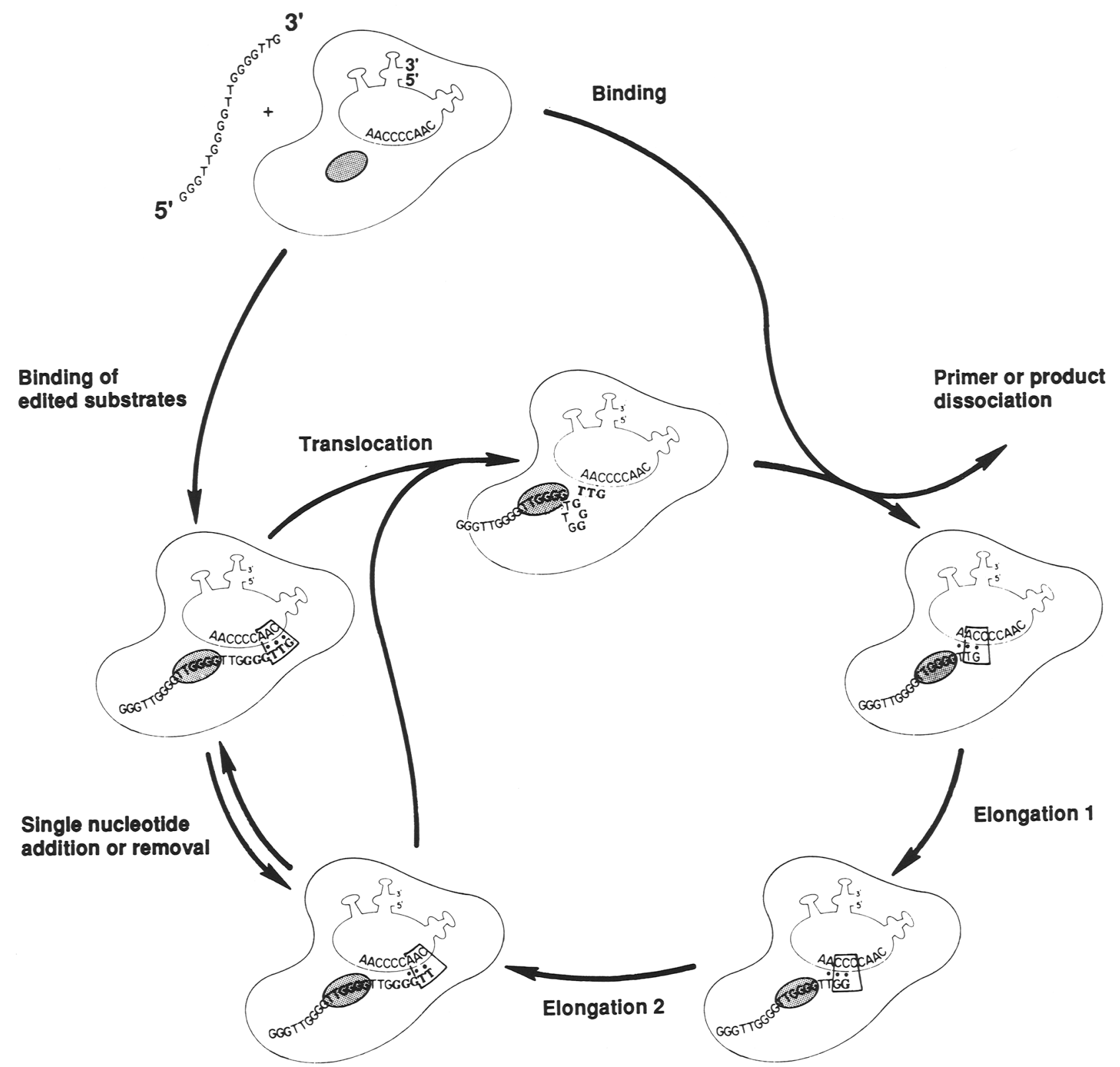

Figure 6. The telomerase cycle, a model for the multiple activities of Tetrahymena telomerase. Active telomerase contains both protein and RNA components, with the RNA adopting possible secondary structure (Romero and Blackburn 1991). Two sites are proposed to be involved in the "binding" of primer, shown here as binding of $d\left(G_{3} T_{2} G\right)_{3}$ : the primer 3 ' end is bound at the template site, shown here as the template sequence itself $\left(3^{\prime}\right.$-AACCCCAAC-5'), whereas the adjacent primer sequence is bound at the anchor site (indicated by a shaded oval). A short lag occurs after primer or nucleotide binding before nucleotide addition (not shown), suggesting a step required for forming the telomerase active site (indicated by a rectangle) preceding nucleotide addition. Primer dissociation may occur before establishment of the active site. Subsequent "elongation" steps, with nucleotides added shown in bold, bring the active site along the template sequence to the $5^{\prime}$ end of the template site. "translocation", or repositioning of the product $3^{\prime}$ end at the $3^{\prime}$ end of the template site, may occur with complete or almost complete copying of the template sequence, before or after addition of the dGTP encoded by the most 5 ' template cytosine residue. Addition of this dGTP corresponds to the described "singlenucleotide addition" activity distinct from elongation. Instead of repositioning, the $3^{\prime}$ end of primer or product bound at the $5^{\prime}$ end of the template sequence can also undergo "nucleotide removal", or cleavage. During repositioning, product may dissociate before its 3 ' end re-establishes stable alignment with the 3 ' end of the template site. Hypothesized base-pairing interactions between the template RNA and primer or product DNA are indicated by dots between base-paired residues. Only 3 bp of interaction between product and template may be maintained during elongation. 
karyotic, and vaccinia virus DNA-dependent RNA polymerases (for review, see Kassavetis and Geiduschek 1993). The RNA polymerases catalyze a $3^{\prime} \rightarrow 5^{\prime}$ nucleolytic product cleavage that is distinct from pyrophosphorolysis, the resynthesis of nucleotide triphosphates from pyrophosphate and the $3^{\prime}$ residue of a polynucleotide (Kassavetis et al. 1986). In reactions with telomerase, the addition of $0.1 \mathrm{~mm}$ pyrophosphate had no effect on the cleavage reaction, whereas the addition of 1 mM pyrophosphate inhibited synthesis of all products, independent of prior cleavage (not shown). It is unlikely that low levels of pyrophosphate added to telomerase reactions as a contaminant of nucleotide stocks, or pyrophosphate accumulated under telomerase reaction conditions, could stimulate significant pyrophosphorolysis. The same extent of cleavage occurs in reactions with $30 \mu \mathrm{M}, 300 \mu \mathrm{M}$, or $3 \mathrm{~mm}$ total nucleotide concentration, and no lag is observed in synthesis of cleaved products relative to longer products of the same primer (not shown).

Cleavage by the RNA polymerases is enhanced at sites of halting or pausing of transcription on a template (Surratt et al. 1991; Borukhov et al. 1992, 1993; Izban and Luse 1992; Reines 1992; Reines et al. 1992; Wang and Hawley 1993). Cleavage by telomerase was also predominantly observed with the inhibition of elongation, by formation of a stable enzyme-product complex (as for $\mathrm{pBRG}_{4} \mathrm{~T}_{2} \mathrm{G}$; stability data not shown, but note plateau in product synthesis with time in Fig. 31, by mismatch of the primer $3^{\prime}$ end with the RNA template [as with $\left.d\left(G_{3} T_{2} G\right)_{2} G_{3} T_{3} G\right]$, or by elongation to the end of the template, where telomerase pauses in synthesis/Greider 1991b). The template position specificity of pausing may determine the template position specificity observed for cleavage. After cleavage by the RNA polymerases of one or more nucleotides from a transcript $3^{\prime}$ end, the new $3^{\prime}$ end of a cleaved RNA that was $\geqslant 5$ (Surratt et al. 1991; Borukhov et al. 1993), 10 (Izban and Luse 1992), or 18 (Hagler and Shuman 1993) nucleotides in length remained associated with the polymerase enzyme and can be elongated subsequently at high efficiency. Telomerase also elongated the new $3^{\prime}$ end of cleaved substrates as short as 11 residues (e.g., see Fig. 4B, primer $\left.\mathrm{d}\left(\mathrm{G}_{3} \mathrm{~T}_{2} \mathrm{G}\right)_{2}\right)$.

Factors promoting cleavage have been separated from both bacterial and eukaryotic RNA polymerase enzymes (for review, see Kassavetis and Geiduschek 1993). These factors, when added to the polymerase enzyme, allow transcript readthrough at sites of transcriptional pausing, indicating that cleavage facilitates transcript elongation. Similarly, product cleavage could enhance the ability of telomerase to maintain its association with a chromosome end during a temporary halt in elongation. Alternatively, cleavage of substrate DNAs by telomerase could provide a mechanism for conversion of substrates created by other DNA cleavage enzymes to ones suitable for elongation with telomeric repeats. Although the effect of template-mispaired nucleotides on transcript cleavage by the RNA polymerases has not been tested, the ability of telomerase to remove template-mispaired as well as template-paired residues from a primer $3^{\prime}$ terminus suggests that the cleavage reaction could provide a proofreading mechanism for enzymes involved in single-stranded polynucleotide synthesis.

\section{Telomerase substrates in vivo}

Primers for telomerase in vivo, chromosome ends, are unlikely to exist as long regions of single-stranded DNA devoid of interacting proteins. Instead, the region of single-stranded DNA at a chromosome terminus may be limited by single- and double-stranded DNA-binding proteins, secondary structure, and complementary strand DNA synthesis. We found that using substrates of short single-stranded DNA, especially at high primer concentration, telomerase-synthesized telomeric repeats in a nonprocessive fashion as observed in vivo ( $\mathrm{Yu}$ et al. 1990; Yu and Blackburn 1991). The concentration of primer required for an efficient elongation reaction in vitro may be irrelevant in vivo, because of other factors regulating association of telomerase with substrate DNA. However, variation in the number of substrate chromosome ends present in a cell, for example, with the cell cycle, could influence telomerase activities.

Telomere elongation by telomerase must be regulated for each individual chromosome and, coordinately, for all the chromosomes in a cell. The presence of telomerase activity in a broad range of eukaryotic cells and the overall similarity of Tetrahymena and human telomerase primer specificity /Greider and Blackburn 1987; Blackburn et al. 1989; Morin 1989, 1991; Harrington and Greider 1991) and processivity (Greider 1991b; Prowse et al. 1993) suggest that the mechanisms of primer binding and elongation by telomerase may have been conserved in evolution. Interestingly, telomerase from immortalized mouse cells appears to catalyze only nonprocessive elongation (Prowse et al. 1993). Thus, different organisms may have specifically adapted telomerase activities. The activities we describe for Tetrahymena telomerase increase our knowledge of possible functions of this unique DNA polymerase and suggest similarities between telomerase and other polymerase enzymes.

\section{Materials and methods}

\section{Purification of primers}

Primers were synthesized by Operon Technologies (Alameda, CA). Crude primers resuspended in $\mathrm{H}_{2} \mathrm{O}$ or TE $[10 \mathrm{mM}$ Tris (pH 8.0) $1 \mathrm{mM}$ EDTA] were mixed with an equal volume of deionized formamide, heated to $\geqslant 65^{\circ} \mathrm{C}$, cooled on ice, then loaded and electrophoresed in $10-20 \%$ acrylamide $/ 7 \mathrm{M}$ urea gels. The region of the gel containing full-length primer, determined by illumination with shortwave UV light, was excised, crushed, and incubated in diethylpyrocarbonate (DEP)-treated $\mathrm{H}_{2} \mathrm{O}$ overnight at $37^{\circ} \mathrm{C}$. Eluted primers were desalted into DEP- $\mathrm{H}_{2} \mathrm{O}$ with NAP-5 columns (Pharmacia), dried, and resuspended in DEP$\mathrm{H}_{2} \mathrm{O}$. Primer concentrations were determined by absorbance at $260 \mathrm{~nm}$ of a diluted aliquot of the primer stock.

\section{Telomerase preparation}

Telomerase was prepared according to a modification of Greider 
and Blackburn (1987; L. Harrington and C. Greider, unpubl.). Tetrahymena of the strain SB 210 were grown to a density of $2.5 \times 10^{5} / \mathrm{ml}$ in 12 liters of standard media $(2 \%$ proteose peptone, $0.2 \%$ yeast extract, $10 \mu \mathrm{M} \mathrm{FeCl}_{3}$ ) with $250 \mu \mathrm{g} /$ liter each of ampicillin and streptomycin, harvested by centrifugation, resuspended in 8 liters of Dryls starvation media $11.7 \mathrm{~mm}$ sodium citrate, $2.4 \mathrm{~mm}$ sodium phosphate, $2 \mathrm{mM} \mathrm{CaCl}$ ), and incubated at $30^{\circ} \mathrm{C}$ with shaking at $150 \mathrm{rpm}$ for $18 \mathrm{hr}$. Cells were again harvested by centrifugation and resuspended in volume equal to the cell pellet of TMG $[10 \mathrm{mM}$ Tris acetate $(\mathrm{pH} 8.0), 1 \mathrm{~mm}$ $\mathrm{MgCl}_{2}, 10 \%$ glycerol] with $10 \mathrm{~mm} \beta$-mercaptoethanol ( $\beta$-me) and protease inhibitors (usually $0.1 \mathrm{mM}$ PMSF and $10 \mu \mathrm{M}$ pepstatin). Lysis was accomplished with the addition of $0.2 \%$ NP40 while stirring at $4^{\circ} \mathrm{C}$ for $15 \mathrm{~min}$. The supernatant from centrifugation of the lysed extract at 30,000 rpm for $1 \mathrm{hr}$ in a SW41 rotor at $4^{\circ} \mathrm{C}$ was loaded on a $40-\mathrm{ml}$ column of heparin-agarose (Bio-Rad) equilibrated in TMG with $\beta$-me and inhibitors as described above. Telomerase was eluted with equilibration buffer with $0.2 \mathrm{M}$ potassium glutamate $(\mathrm{Kglu})$ and frozen in liquid nitrogen. Fractions containing maximal telomerase activity were loaded on an 8- to $10-\mathrm{ml}$ column of DEAE-agarose (Bio-Rad), equilibrated in TMG, $\beta$-me, protease inhibitors, and $0.2 \mathrm{M} \mathrm{Kglu}$. Telomerase was eluted with a $50 \mathrm{ml}$ gradient from $0-$ to $0.6-\mathrm{M}$ Kglu. Fractions with maximal telomerase activity were pooled $(\sim 3 \mathrm{ml})$, aliquoted, and frozen in liquid nitrogen. Protein concentrations were determined by a Bradford assay with Bio-Rad dye reagent. This preparation of telomerase was purified 56-fold from the cytoplasmic S-100 extract.

\section{Glycerol gradient sedimentation}

Telomerase purified over heparin-agrose and DEAE-agarose, as above $(0.45 \mathrm{ml})$, was sedimented in an $11-\mathrm{ml}, 15-35 \%$ glycerol gradient. The gradient buffer contained $10 \mathrm{mM}$ Tris acetate $1 \mathrm{pH}$ $8.01,1 \mathrm{~mm} \mathrm{MgCl}_{2}, 1 \mathrm{~mm}$ DTT, and $0.1 \mathrm{M}$ sodium acetate. The gradient was centrifuged for $20 \mathrm{hr}$, at $40,000 \mathrm{rpm}$ and $4^{\circ} \mathrm{C}$ in a SW41 rotor; 40 fractions were collected from the bottom of the gradient (fraction 1 was maximal density). Most proteins remained in fractions of lower percentage glycerol than telomerase, whereas most abundant small nuclear ribonucleoproteins sedimented farther into the gradient. The peak of telomerase activity (fraction 24) corresponds to sedimentation of a molecular mass of $\sim 270 \mathrm{kD}$. This preparation of telomerase (fractions 22-26 inclusive) was purified 520-fold from the cytoplasmic S-100 extract.

\section{Telomerase reactions}

A mixture of reaction components excluding telomerase was made in half the reaction volume. An equal volume of telomerase either not diluted (glycerol gradient fractions) or diluted $1: 10$ in TMG (all other reactions) was added to start the reaction. Final concentrations of reaction components were $50 \mathrm{mM}$ Tris acetate $(\mathrm{pH} 8.5), 1 \mathrm{~mm}$ spermidine, $5 \mathrm{~mm} \beta-\mathrm{me}, 100 \mathrm{~mm}$ potassium acetate, $500 \mu \mathrm{M}$ TTP, $1 / 40$ volume of $800 \mathrm{Ci} / \mathrm{mmole}$ of $\left[\alpha^{-32}\right.$ P]dGTP (New England Nuclear), and primer DNA. Unless otherwise noted, primer concentrations were $800 \mathrm{~nm}$ and reaction time was $20 \mathrm{~min}$ at $30^{\circ} \mathrm{C}$, with a typical reaction volume of $20-40 \mu \mathrm{l}$. For reactions that were preincubated with RNase (Fig. 1B), telomerase diluted 1:10 in TMG was incubated at $30^{\circ} \mathrm{C}$ for $15 \mathrm{~min}$ with $1 / 100$ volume of $20-50 \mathrm{U} / \mu \mathrm{l}$ of DNase-free RNase (Boehringer Mannheim) before addition of the remaining, premixed reaction components. Samples not RNased in the same experiment were incubated in parallel at $30^{\circ} \mathrm{C}$ for $15 \mathrm{~min}$ before the addition of the reaction mix; this preincubation had no effect on product DNA synthesis (not shown). A 1/30 volume of RNase was added to reactions after $20 \mathrm{~min}$ for the samples in Figure 3. Telomerase reactions were stopped with 2.5 volumes of $10 \mathrm{~mm}$ Tris (pH 7.5), 21 mM EDTA, extracted with an equal volume of phenol, and precipitated with $\sim 1 \mu \mathrm{g}$ of tRNA, 0.3 volumes of $2.5 \mathrm{M}$ ammonium acetate, and 4 volumes of cold ethanol at $20^{\circ} \mathrm{C}$ for $\sim 0.5-1 \mathrm{hr}$. After centrifugation for $20 \mathrm{~min}$ at $20^{\circ} \mathrm{C}$, pellets were dried and resuspended in formamide with bromphenol blue and xylene cyanol. After boiling and cooling on ice, samples were electrophoresed on $10.5 \%$ acrylamide/7 M urea gels unless otherwise noted. Gels were dried and exposed to film, generally overnight. For quantitation, dried gels were exposed to Fuji PhosphorImager screens for $1 \mathrm{hr}$, and products were quantitated with Fuji imaging software.

\section{Terminal deoxytransferase reactions}

In a volume of $10 \mu \mathrm{l}, \sim 0.3 \mu \mathrm{g}$ of primer was reacted with $0.5 \mu \mathrm{l}$ of $3000 \mathrm{Ci} / \mathrm{mmole}$ of $\left[\alpha^{-32} \mathrm{P}\right] \mathrm{ddATP}$ (Amersham) and $0.5 \mu \mathrm{l}$ of calf thymus terminal deoxynucleotidyl transferase (IBI) in the $\mathrm{Mg}^{2+}$ reaction buffer supplied by the the manufacturer [final concentrations of $140 \mathrm{~mm}$ potassium cacodylate $(\mathrm{pH} 7.2), 30 \mathrm{~mm}$ Tris base, $4 \mathrm{mM} \mathrm{MgCl}_{2}, 0.1 \mathrm{mM}$ DTT]. Labeling proceeded for 10 min at $37^{\circ} \mathrm{C}$ before the addition of EDTA to stop the reaction. Labeling efficiency varied with the length and sequence of the primer; roughly equivalent counts of ${ }^{32} \mathrm{P}$-labeled primers were loaded on gels rather than equivalent amounts of DNA.

\section{Acknowledgments}

We thank Drs. Stewart Shuman, Dan Marshak, Eric Henderson, Paul Kaufman, and members of the Greider laboratory for critical reading of the manuscript. K.C. is a Burroughs Wellcome Fund Fellow of the Life Sciences Research Foundation. C.W.G. is a Pew Scholar in the Biomedical Sciences. This work was supported by National Institutes of Health grant GM43080 to C.W.G.

The publication costs of this article were defrayed in part by payment of page charges. This article must therefore be hereby marked "advertisement" in accordance with 18 USC section 1734 solely to indicate this fact.

\section{Note added in proof}

M.S. Lee and E.H. Blackburn (in prep.) also have obtained independent evidence for nonprocessive elongation of short primers.

\section{References}

Allsopp, R.C., H. Vaziri, C. Patterson, S. Goldstein, E.V. Younglai, A.B. Futcher, C.W. Greider, and C.B. Harley. 1992. Telomere length predicts the replicative capacity of human fibroblasts. Proc. Natl. Acad. Sci. 89: 10114-10118.

Biessmann, H. and J.M. Mason. 1988. Progressive loss of DNA sequences from terminal chromosome deficiences in Drosophila melanogaster. EMBO $/$. 7: 1081-1086.

Blackburn, E.H. 1991. Structure and function of telomeres. $\mathrm{Na}$ ture 350: 569-573.

Blackburn, E.H., C.W. Greider, E. Henderson, M.S. Lee, J. Shampay, and D. Shippen-Lentz. 1989. Recognition and elongation of telomeres by telomerase. Genome 31: 553-560.

Borukhov, S., A. Polyakov, V. Nikiforov, and A. Goldfarb. 1992. GreA protein: A transcription elongation factor from Escherichia coli. Proc. Natl. Acad. Sci. 89: 8899-8902.

Borukhov, S., V. Sagitov, and A. Goldfarb. 1993. Transcript cleavage factors from E. coli. Cell 72: 459-466. 
Counter, C.M., A.A. Avilion, C.E. LeFeuvre, N.G. Stewart C.W. Greider, C.B. Harley, and S. Bacchetti. 1992. Telomere shortening associated with chromosome instability is arrested in immortal cells which express telomerase activity. EMBO I. 11: 1921-1929.

Greider, C.W. 1990. Telomeres, telomerase and senescence. Bioessays 12: 363-369.

. 199la. Chromosome first aid. Cell 67: 645-647.

. 1991b. Telomerase is processive. Mol. Cell. Biol. 11: 4572-4580.

Greider, C.W. and E.H. Blackburn. 1985. Identification of a specific telomere terminal transferase activity in Tetrahymena extracts. Cell 43: 405-413.

- 1987. The telomere terminal transferase of Tetrahymena is a ribonucleoprotein enzyme with two kinds of primer specificity. Cell 51: 887-898.

-1989. A telomeric sequence in the RNA of Tetrahymena telomerase required for telomere repeat synthesis. Nature 337: 331-337.

Hagler, J. and S. Shuman. 1993. Nascent RNA cleavage by purified ternary complexes of vaccinia RNA polymerase. $J$. Biol. Chem. 268: 2166-2173.

Harley, C.B., A.B. Futcher, and C.W. Greider. 1990. Telomeres shorten during ageing of human fibroblasts. Nature 345: $458-460$.

Harrington, L.A. and C.W. Greider. 1991. Telomerase primer specificity and chromosome healing. Nature 353: 451-454.

Hastie, N.D., M. Dempster, M.G. Dunlop, A.M. Thompson, D.K. Green, and R.C. Allshire. 1990. Telomere reduction in human colorectal carcinoma and with ageing. Nature 346: 866-868.

Izban, M.G. and D.S. Luse. 1992. The RNA polymerase II ternary complex cleaves the nascent transcript in a $3^{\prime}-5^{\prime}$ direction in the presence of elongation factor SII. Genes \& Dev. 6: 1342-1356.

Kassavetis, G.A. and E.P. Geiduschek. 1993. RNA polymerase marching backward. Science 259: 944-945.

Kassavetis, G.A., P.G. Zentner, and E.P. Geiduschek. 1986. Transcription at bacteriophage $\mathrm{T} 4$ variant late promoters. $I$. Biol. Chem. 261: 14256-14265.

Levis, R.W. 1989. Viable deletions of a telomere from a Drosophila chromosome. Cell 58: 791-801.

Lundblad, V. and I.W. Szostak. 1989. A mutant with a defect in telomere elongation leads to senescence in yeast. Cell 57: 633-643.

McClintock, B. 1941. The stability of broken ends of chromosomes in Zea mays. Genetics 26: 234-282.

Morin, G.B. 1989. The human telomere terminal transferase enzyme is a ribonucleoprotein that synthesizes TTAGGG repeats. Cell 59: 521-529.

. 1991. Recognition of a chromosome truncation site associated with $\alpha$-thalassaemia by human telomerase. Nature 353: 454-456.

Olovnikov, A.M. 1973. A theory of marginotomy. J. Theor. Biol. 41: $181-190$.

Prowse, K.R., A.A. Avilion, and C.W. Greider. 1993. Identification of a nonprocessive telomerase activity from mouse cells. Proc. Natl. Acad. Sci. 90: 1493-1497.

Reines, D. 1992. Elongation factor-dependent transcript shortening by template-engaged RNA polymerase II. /. Biol. Chem. 267: 3795-3800.

Reines, D., P. Ghanouni, Q. Li, and J. Mote Jr. 1992. The RNA polymerase II elongation complex. J. Biol. Chem. 267: 15516-15522.

Romero, D.P. and E.H. Blackburn. 1991. A conserved secondary structure for telomerase RNA. Cell 67: 343-353.
Surratt, C.K., S.C. Milan, and M.J. Chamberlin. 1991. Spontaneous cleavage of RNA in ternary complexes of Escherichia coli RNA polymerase and its significance for the mechanism of transcription. Proc. Natl. Acad. Sci. 88: 7983-7987.

von Hippel, P.H., D.G. Bear, W.D. Morgan, and J.A. McSwiggen. 1984. Protein-nucleic acid interactions in transcription. Annu. Rev. Biochem. 53: 389-446.

Wang, D. and D.K. Hawley. 1993. Identification of a $3^{\prime}-5^{\prime}$ exonuclease activity associated with human RNA polymerase II. Proc. Natl. Acad. Sci. 90: 843-847.

Watson, J.D. 1972. Origin of concatemeric T4 DNA. Nature New Biol. 239: 197-201.

Yu, G.-L. and E.H. Blackburn. 1991. Developmentally programmed healing of chromosomes by telomerase in Tetrahymena. Cell 67: 823-832.

Yu, G.-L., J.D. Bradley, L.D. Attardi, and E.H. Blackburn. 1990. In vivo alteration of telomere sequences and senescence caused by mutated Tetrahymena telomerase RNAs. Nature 344: $126-132$. 


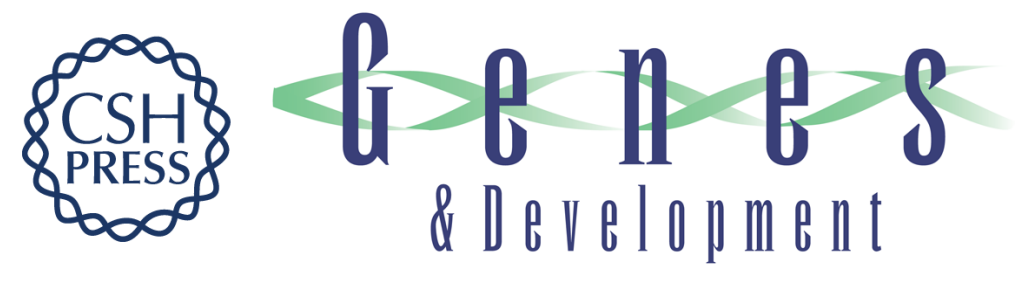

\section{Tetrahymena telomerase catalyzes nucleolytic cleavage and nonprocessive elongation.}

K Collins and C W Greider

Genes Dev. 1993, 7:

Access the most recent version at doi:10.1101/gad.7.7b.1364

References This article cites 36 articles, 13 of which can be accessed free at:

http://genesdev.cshlp.org/content/7/7b/1364.full.html\#ref-list-1

License

Email Alerting

Service

Receive free email alerts when new articles cite this article - sign up in the box at the top right corner of the article or click here.

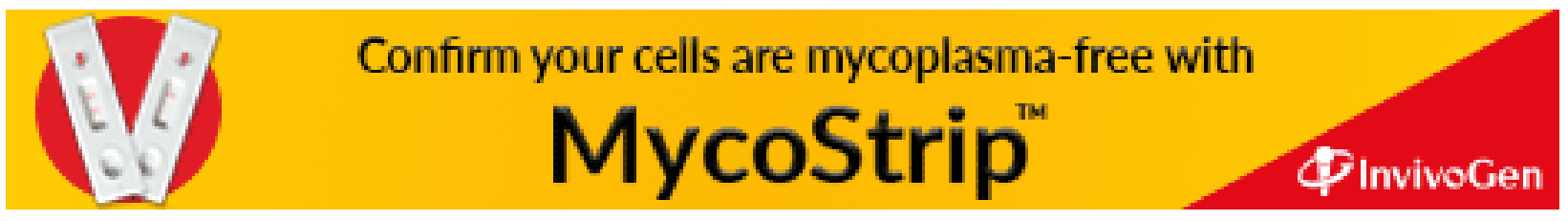

